\title{
Análise do efeito do uso das órteses de punho na musculatura do antebraço: uma revisão comentada da literatura
}

\section{Analysis of the effects of the use of wrist orthoses in the forearm musculature: a commented literature review}

\author{
Adriana Maria Valladão Novais Rodrigues ${ }^{1}$, Andressa Dias Miranda ${ }^{2}$, \\ Giselle dos Santos Pereira², Valdiane Alves Leal ${ }^{2}$, Antônio Ferreira Ávila ${ }^{3}$
}

RODRIGUES, A. M. V. N.; MIRANDA, A. D.; PEREIRA, G. dos S.; LEAL, V. A.; ÁVILA, A. F. Análise do efeito do uso das órteses de punho na musculatura do antebraço: uma revisão comentada da literatura. Rev. Ter. Ocup. Univ. São Paulo, v. 18, n. 1, p. 30-37, jan./abr., 2007.

RESUMO: Terapeutas Ocupacionais recomendam órteses de punho como recurso terapêutico na reabilitação de pacientes com desordens do punho relacionadas ao esforço da musculatura do antebraço. Contudo, existem achados na literatura de que as órteses ao invés de reduzirem a carga na musculatura do antebraço, aumentam a atividade eletromiográfica dos flexores e extensores, sugerindo que a meta de descanso nem sempre é alcançada. Portanto, o objetivo deste estudo foi realizar uma revisão comentada da literatura através da análise criteriosa de artigos científicos que investigassem o efeito do uso das órteses de punho na musculatura do antebraço. Foram realizadas consultas nas bases eletrônicas de dados no período de 1995 a 2004, e quatro artigos foram selecionados, sendo feita uma análise da qualidade das evidências de acordo com a metodologia proposta por Law et al. Constatou-se uma falta de consenso entre os autores pesquisados quanto à atividade eletromiográfica dos músculos do antebraço durante o uso de órteses de punho.

DESCRITORES: Eletromiografia. Antebraço. Terapia ocupacional. Literatura de revisão. Traumatismos do punho/reabilitação.

\footnotetext{
${ }^{1}$ Professora Assistente do Depto de Terapia Ocupacional da Universidade Federal de Minas Gerais. Mestre em Engenharia Mecânica UFMG.

${ }^{2}$ Terapeuta Ocupacional - UFMG.

${ }^{3}$ Professor Adjunto do Depto de Engenharia Mecânica da Universidade Federal de Minas Gerais.

Endereço para correspondência: Adriana M. Valladão Novais Rodrigues. Rua Ubá 351/703 - Belo Horizonte, MG. CEP: 31110-110. email:avaladao@ufmg.br
} 


\section{INTRODUÇÃO}

força de preensão intermitente é essencial na
maioria das atividades manuais, bem como
em trabalhos industriais e atividades esportivas (HAGG et al.,1997; MILERAD, 1997). Indispensável à função manual, a força de preensão, que é basicamente realizada pela flexão dos dedos ativada pelos músculos flexores intrínsecos e extrínsecos da mão, associada com a posição do punho, tem sido estudada a partir da avaliação da atividade de tais músculos, sem que, contudo, seja estudada, profundamente, a atividade muscular dos extensores do punho (ARMSTRONG et al., 1979). Entretanto, estudos indicam um predomínio da atividade muscular dos extensores sobre a atividade da musculatura flexora durante a preensão (MATSUSHITA et al., 1995; HAGG et al., 1997; MILERAD, 1997).

Segundo Matsushita et al. (1995), durante a fase de abertura da mão na atividade de preensão, os músculos extensor ulnar do carpo (EUC) e flexor ulnar do carpo (FUC) são os mais ativos, e durante o movimento de agarrar (fechar a mão), o músculo extensor radial curto do carpo (ERCC) é o mais ativo associado à marcada atividade do extensor ulnar do carpo (EUC) e à moderada atividade do extensor radial longo do carpo (ERLC). Hägg et al., e Milerad em 1997, relatam que durante as atividades manuais intermitentes, o esforço e a fadiga são maiores no lado extensor, porque os extensores do punho possuem a função dupla de realizar o movimento de extensão e de estabilizar o punho durante a preensão.

A maior exigência à força de preensão estática e a relativa falta de pausas dos extensores têm sido descritas como as prováveis causas do aumento do grau de fadiga muscular (HAGG et al., 1997; MILERAD, 1997). A ativação muscular e a distribuição da fadiga no antebraço são de grande importância para o entendimento das desordens do punho relacionadas com o esforço muscular, pois, estudos indicam que trabalhos manuais de longa duração envolvendo o esforço da musculatura do antebraço estão associados a essas desordens (MOORE; GARG, 1994; HAGG et al., 1997).

$\mathrm{Na}$ tentativa de minimizar os efeitos das desordens do punho, tais como, tendinite de flexores e extensores do punho, fraqueza dos músculos do punho, lesões por esforços repetitivos, terapeutas ocupacionais têm utilizado e recomendado órteses de punho como recurso terapêutico na reabilitação (CALLINAN, 1999). Estes dispositivos têm como objetivos promover a restrição do movimento do punho, buscar o posicionamento funcional da articulação envolvida e oferecer descanso para estruturas fracas, inflamadas e fatigadas (CALLINAN, 1999). A indicação deste equipamento tem como princípio a estabilização passiva do punho, através de uma órtese estática em posição funcional, com o objetivo de reduzir a carga da musculatura extensora do punho (JOHANSON et al., 1998). Contudo, existem achados de que o uso de órteses ao invés de reduzir a carga dessa musculatura extensora, aumenta a atividade eletromiográfica dos flexores e extensores do punho, sugerindo que a meta de descanso dessas estruturas nem sempre são efetivamente alcançadas (CALLINAN, 1999).

Diante desta controvérsia e, considerando que a indicação do uso de órtese é comum na clínica da Terapia Ocupacional frente a estas desordens, faz-se necessário buscar evidências científicas sobre a real indicação e função das órteses de punho para este fim. Desta forma, o objetivo deste estudo foi realizar uma revisão comentada da literatura por intermédio da seleção e da análise criteriosa de artigos científicos que investigassem quais os reais efeitos das órteses de punho na atividade muscular do antebraço e que verificassem a adequação da indicação deste tipo de equipamento no tratamento de desordens de punho.

\section{METODOLOGIA}

A pesquisa foi feita através de consultas em bibliotecas e nas bases eletrônicas Medline, Lilacs, Pubmed e Bireme, seguindo como estratégia de busca a língua inglesa, com investigação restrita ao período de 1995 até 2004. As palavras-chave utilizadas foram: wrist orthosis em combinação com manual work, forearm muscle activity, electromyography; e electromyography associada com wrist splint e forearm muscle activity, e ainda, electromyography mais forearm muscle activity em combinação com wrist, splint e orthotic.

Os artigos foram selecionados por três pesquisadoras a partir da leitura dos títulos e resumos, sendo que os critérios de inclusão foram: 1. população: adultos; 2. tipo de intervenção realizada: o uso de órteses de punho; 3. desfecho investigado: atividade muscular no antebraço, via eletromiografia, com o uso de órteses de punho durante atividades funcionais. Quando o título ou o resumo do estudo não explicitava esses três critérios, o artigo era automaticamente descartado da seleção.

Os artigos que atingiram os critérios de inclusão definidos, anteriormente, foram analisados criticamente, segundo a metodologia proposta por Law et al. (1998), que sugere a criação de um fluxograma para organização dos artigos discutidos. 


\section{RESULTADOS}

Na revisão da literatura realizada foi identificado um total de 430 artigos, dos quais 18 foram pré-selecionados pelo conteúdo do título, e desses, 14 foram descartados após a leitura do resumo por não preencherem os critérios de inclusão anteriormente definidos.

Para o presente estudo, foram incluídos quatro artigos, sendo estes resumidos de forma padronizada, com base nos seguintes tópicos: autor(es); objetivo do estudo; caracterização da amostra; desenho do estudo; e resultados; conforme pode ser visualizado no Quadro 1.

Quadro 1 - Resumo das informações dos artigos selecionados para esta revisão comentada da literatura de acordo com metodologia proposta por Law et al. (1998).

\begin{tabular}{|c|c|c|c|c|c|c|}
\hline \multirow[t]{2}{*}{ Autor(es) } & \multirow[t]{2}{*}{ Objetivo do estudo } & \multirow{2}{*}{$\begin{array}{l}\text { Caracterização dos } \\
\text { sujeitos }\end{array}$} & \multirow{2}{*}{\begin{tabular}{|l|}
$\begin{array}{l}\text { Desenho do } \\
\text { estudo }\end{array}$ \\
Tipo de \\
intervenção \\
\end{tabular}} & \multicolumn{3}{|l|}{ Resultados } \\
\hline & & & & Tarefas investigadas & $\begin{array}{l}\text { Coleta dos dados e tempo } \\
\text { de uso da órtese }\end{array}$ & \\
\hline $\begin{array}{l}\text { JANSEN } \text { et } \\
\text { al. (1997) }\end{array}$ & $\begin{array}{l}\text { Comparar a eficácia de } \\
\text { três tipos de órteses } \\
\text { extensoras do punho na } \\
\text { diminuição da atividade } \\
\text { elétrica dos extensores } \\
\text { do punho durante a } \\
\text { realização de } \\
\text { atividades. }\end{array}$ & $\begin{array}{l}11 \text { mulheres e } 2 \\
\text { homens (com mão } \\
\text { dominante direita, } \\
\text { sem história de } \\
\text { desordens do } \\
\text { membro superior), } \\
\text { com média de idade } \\
\text { de } 27.7 \text { anos. }\end{array}$ & $\begin{array}{l}\text { Três órteses de } \\
\text { punho: volar, } \\
\text { dorsal e } \\
\text { semicircular } \\
\text { com apoio } \\
\text { ventral } \\
\text { (personalizada) } \\
\text { E mão livre. } \\
\text { Punho mantido } \\
\text { a } 15^{\circ} \text { de } \\
\text { dorsiflexão. } \\
\text { Material: NCM } \\
\text { Preferred. }\end{array}$ & $\begin{array}{l}3 \text { tarefas manuais de } \\
\text { erguer (erguer pasta, } \\
\text { erguer sacola de } \\
\text { compras e erguer uma } \\
\text { pasta de papéis). } \\
3 \text { tarefas de preensão } \\
\text { (Jamar). }\end{array}$ & $\begin{array}{l}\text { Foram realizadas três } \\
\text { medidas em dias } \\
\text { consecutivos, sem o uso } \\
\text { das órteses e com o uso } \\
\text { delas. Uso das órteses } \\
\text { apenas no momento da } \\
\text { avaliação. } \\
\text { Coleta dos dados } \\
\text { relativos à atividade } \\
\text { eletromiográfica do } \\
\text { extensor radial curto do } \\
\text { carpo e longo do carpo. }\end{array}$ & $\begin{array}{l}\text { A órtese semicircular } \\
\text { reduziu, } \\
\text { significativamente, }(6 \%) \\
\text { a atividade do extensor } \\
\text { radial curto do carpo } \\
\text { durante a atividade de } \\
\text { erguer, comparado com a } \\
\text { mão livre. Com o uso das } \\
\text { outras órteses (volar e } \\
\text { dorsal) não foram } \\
\text { encontradas alterações na } \\
\text { musculatura extensora }\end{array}$ \\
\hline $\begin{array}{l}\text { BULTHAUP } \\
\text { et al. } \\
(1999)\end{array}$ & $\begin{array}{l}\text { Investigar a atividade } \\
\text { muscular flexora e } \\
\text { extensora do antebraço } \\
\text { evidente quando os } \\
\text { participantes fazem uso } \\
\text { de dois tipos de órteses } \\
\text { comercialmente } \\
\text { fabricadas para } \\
\text { posicionamento do } \\
\text { punho em extensão. }\end{array}$ & $\begin{array}{l}17 \text { mulheres (com a } \\
\text { mão direita } \\
\text { dominante, sem } \\
\text { desordens do } \\
\text { membro superior), } \\
\text { com média de idade } \\
\text { de } 26,6 \text { anos. }\end{array}$ & 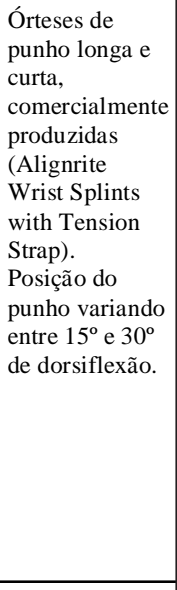 & $\begin{array}{l}\text { Atividades do dia-a- } \\
\text { dia (erguer, esvaziar e } \\
\text { posicionar). }\end{array}$ & $\begin{array}{l}\text { Coleta dos dados } \\
\text { relativos à atividade } \\
\text { eletromiográfica dos } \\
\text { músculos peitoral maior, } \\
\text { trapézio, deltóide médio, } \\
\text { bíceps braquial, cabeça } \\
\text { medial do tríceps, flexor } \\
\text { radial do carpo e extensor } \\
\text { radial curto do carpo. } \\
\text { As coletas foram feitas } \\
\text { em apenas um dia. } \\
\text { Coleta nas três } \\
\text { condições, sem a órtese, } \\
\text { com a órtese longa e com } \\
\text { a órtese curta. } \\
\text { As órteses foram usadas } \\
\text { somente na hora da } \\
\text { avaliação. } \\
\text { Três coletas em cada } \\
\text { condição. }\end{array}$ & $\begin{array}{l}\text { A atividade elétrica foi } \\
\text { maior com os dois tipos } \\
\text { de órteses, em } 4 \text { (peitoral } \\
\text { maior, trapézio, bíceps } \\
\text { braquial e cabeça média } \\
\text { do tríceps) dos } 5 \\
\text { músculos proximais e no } \\
\text { flexor do punho. Não } \\
\text { existiram diferenças } \\
\text { significativas entre o uso } \\
\text { da órtese longa ou curta } \\
\text { para os músculos } \\
\text { proximais. A órtese longa } \\
\text { resultou em uma maior } \\
\text { atividade muscular dos } \\
\text { músculos extensores do } \\
\text { punho e a órtese curta não } \\
\text { teve efeito sobre esta } \\
\text { musculatura. }\end{array}$ \\
\hline $\begin{array}{l}\text { BURTNER } \text { et } \\
\text { al. }(2003)\end{array}$ & $\begin{array}{l}\text { Comparar a força, a } \\
\text { destreza e ativação } \\
\text { muscular em indivíduos } \\
\text { com artrite reumatóide } \\
\text { durante o uso de } \\
\text { diferentes splints. } \\
\text { Foram investigados os } \\
\text { seguintes músculos: } \\
\text { flexor radial do carpo } \\
\text { (FRC) e extensor radial } \\
\text { longo do carpo } \\
\text { (ERLC), bíceps, } \\
\text { tríceps, deltóide } \\
\text { anterior e medial, } \\
\text { peitoral maior, e } \\
\text { trapézio superior. }\end{array}$ & $\begin{array}{l}4 \text { mulheres e } 1 \\
\text { homem, com idade } \\
\text { média de } 48,4 \text { anos, } \\
\text { com artrite } \\
\text { reumatóide } \\
\text { comprovada pelos } \\
\text { critérios do Colégio } \\
\text { Americano de } \\
\text { Reumatologia, com } \\
\text { tempo da doença em } \\
\text { média de } 16,2 \text { anos, } \\
\text { e sem contraturas ou } \\
\text { deformidades nos } \\
\text { braços e nas mãos. }\end{array}$ & $\begin{array}{l}\text { Órteses: } \\
\text { estática, em } \\
\text { espiral e } \\
\text { dinâmica } \\
\text { punho-mão. } \\
\text { E mão livre. }\end{array}$ & $\begin{array}{l}\text { Foi usado o Jamar } \\
\text { para medir a força de } \\
\text { preensão, e o pinch } \\
\text { meter estandardizado } \\
\text { para medir a força da } \\
\text { pinça de dois e três } \\
\text { pontos e pinça lateral. } \\
\text { E para avaliar a } \\
\text { destreza manual foi } \\
\text { usado o Nine-Role } \\
\text { Peg Test. A EMG foi } \\
\text { registrada durante } \\
\text { todas essas tarefas. }\end{array}$ & Não foi relatado. & $\begin{array}{l}\text { Não houve diferença } \\
\text { significativa na atividade } \\
\text { EMG dos músculos } \\
\text { flexores e extensores do } \\
\text { punho durante o uso dos } \\
\text { diferentes splints. Os } \\
\text { resultados mostraram que } \\
\text { a ativação muscular é } \\
\text { mais dependente da tarefa } \\
\text { realizada do que do tipo } \\
\text { de órtese que é utilizada. }\end{array}$ \\
\hline
\end{tabular}


Continuação

\begin{tabular}{|c|c|c|c|c|c|c|}
\hline \multirow[t]{2}{*}{ Autor(es) } & \multirow[t]{2}{*}{ Objetivo do estudo } & \multirow{2}{*}{$\begin{array}{l}\text { Caracterização dos } \\
\text { sujeitos }\end{array}$} & \multirow{2}{*}{$\begin{array}{l}\begin{array}{l}\text { Desenho do } \\
\text { estudo }\end{array} \\
\text { Tipo de } \\
\text { intervenção }\end{array}$} & \multicolumn{3}{|l|}{ Resultados } \\
\hline & & & & Tarefas investigadas & $\begin{array}{l}\text { Coleta dos dados e tempo } \\
\text { de uso da órtese }\end{array}$ & \\
\hline $\begin{array}{l}\text { JOHANSSON } \\
\text { et al. (2004) }\end{array}$ & $\begin{array}{l}\text { Investigar a atividade } \\
\text { muscular flexora e } \\
\text { extensora do antebraço } \\
\text { evidente quando os } \\
\text { participantes fazem uso de } \\
\text { dois tipos de órteses para } \\
\text { posicionamento do punho } \\
\text { em extensão. }\end{array}$ & $\begin{array}{l}6 \text { mulheres e } 6 \\
\text { homens, } \\
\text { Média de idade dos } \\
\text { homens: } 38 \text { anos. } \\
\text { Média de idade das } \\
\text { mulheres: } 36 \text { anos. }\end{array}$ & $\begin{array}{l}\text { Órtese volar e } \\
\text { órtese comercial } \\
\text { flexível com } \\
\text { suporte para } \\
\text { polegar (fita } \\
\text { desportiva). } \\
\text { Não informa o } \\
\text { ângulo de } \\
\text { imobilização. } \\
\text { Não informa o } \\
\quad \text { material. }\end{array}$ & $\begin{array}{l}\text { Força de preensão com a } \\
\text { utilização do Jamar; e } \\
\text { atividades manuais } \\
\text { padronizadas: segurar um } \\
\text { cilindro, elevar um } \\
\text { cilindro da mesa, cortar } \\
\text { um arame com alicate e } \\
\text { golpear uma barra de aço } \\
\text { com um taco de borracha. }\end{array}$ & $\begin{array}{l}\text { As coletas foram feitas em } \\
\text { apenas um dia, sem a órtese, } \\
\text { com a órtese volar e com a } \\
\text { órtese comercial. As ótteses } \\
\text { foram usadas somente na } \\
\text { hora da avaliacãão. } \\
\text { Coleta dos dados relativos à } \\
\text { atividade eletromiográfica } \\
\text { dos músculos flexor ulnar do } \\
\text { carpo, flexor superficial dos } \\
\text { dedos, extensor radial longo } \\
\text { do carpo, e extensor ulnar do } \\
\text { carpo. }\end{array}$ & $\begin{array}{l}\text { A órtese desportiva não teve } \\
\text { qualquer efeito na atividade } \\
\text { eletromiográfica dos } \\
\text { músculos flexores e } \\
\text { extensores do punho durante } \\
\text { a preensão. A órtese volar } \\
\text { resultou em um aumento da } \\
\text { atividade eletromiográfica } \\
\text { dos flexores e extensores em } \\
\text { relação a órtese desportiva ou } \\
\text { em relação à mão livre. }\end{array}$ \\
\hline
\end{tabular}

Ao analisar-se os artigos a partir da metodologia proposta por Law et al. (1998), foi observado que cada um deles apresentava variações quanto à caracterização e tamanho da amostra, distinção entre objetivos gerais e específicos, tipos de tarefas investigadas, tipos de órteses e os tipos de materiais utilizados na confecção das mesmas.

Quanto à qualidade das evidências, os artigos selecionados apresentaram variáveis que não foram controladas como: a localização dos eletrodos sobre a musculatura; um número restrito de órteses testadas; três dos quatro estudos contou com a participação de pessoas sem desordens do membro superior; e a falta de tempo para adaptação do uso das órteses, sendo essas utilizadas somente no momento da medição. Esses aspectos não controlados podem interferir na confiabilidade dos estudos apresentados.

Dos quatro artigos incluídos nesta revisão, todos utilizaram metodologia quantitativa, o que favorece a produção de evidências mais fidedignas. Dois dos artigos foram classificados como um estudo experimental randomizado (JANSEN et al., 1997; BULTHAUP et al., 1999) e os demais como estudos quasi experimentais (BURTNER et al., 2003; JOHANSSON et al., 2004).

Quanto às tarefas utilizadas como contexto para verificar a atividade muscular do antebraço, Burtner et al. (2003) utilizaram o Jamar, o pinch meter estandardizado e o NineRole Peg Test como testes padronizados; Johansson et al. (2004) também usaram o Jamar; e os demais estudos usaram atividades variadas (tarefas de preensão, erguer, esvaziar) (JANSEN et al., 1997; BULTHAUP et al., 1999).

Com relação aos resultados da atividade eletromiográfica dos músculos do antebraço durante o uso da órtese, não houve consenso entre os autores pesquisados.

\section{DISCUSSÃO}

Os artigos que compõem esta revisão mediram a atividade eletromiográfica dos seguintes músculos do antebraço: extensores do punho, principalmente, o extensor radial curto do carpo (JANSEN et al., 1997); flexor radial do carpo (BULTHAUP et al., 1999; BURTNER et al, 2003); extensor radial longo do carpo (BURTNER et al, 2003; JOHANSSON et al., 2004); extensor radial curto do carpo (BULTHAUP et al., 1999); extensor ulnar do carpo, flexor ulnar do carpo e flexor superficial dos dedos (JOHANSSON et al., 2004). Dois artigos (BULTHAUP et al., 1999; BURTNER et al, 2003), além dos músculos já descritos, também investigaram outros músculos do membro superior, porém, estes não foram apresentados nessa discussão, por não serem o foco desta revisão.

De acordo com os estudos investigados, é possível apresentar uma análise da atividade eletromiográfica dos músculos do antebraço durante o uso de órteses de punho, conforme demonstrado na Tabela 1. Os dados informam que a atividade eletromiográfica da musculatura extensora do antebraço diminuiu com o uso da órtese semicircular (JANSEN et al., 1997); não houve alteração na atividade dos músculos extensores do punho com o uso das órteses volar e dorsal (JANSEN et al., 1997), órtese curta (BULTHAUP et al., 1999), órtese desportiva (JOHANSSON et al., 2004) e com o uso das três órteses (espiral, estática e dinâmica punho-mão) do estudo de Burtner et al. (2003); ocorreu um aumento da atividade da musculatura extensora do antebraço utilizando a órtese longa (BULTHAUP et al., 1999) e a órtese volar (JOHANSSON et al., 2004). Com relação à musculatura flexora, não houve alteração na atividade dos músculos flexores do punho usando as órteses espiral, estática e dinâmica punho-mão (BURTNER et al., 2003) e órtese desportiva (JOHANSSON et al., 2004); e ocorreu um aumento da atividade da musculatura flexora do antebraço com o uso das órteses longa e curta (BULTHAUP et al., 1999) e da órtese volar (JOHANSSON et al., 2004). 
RODRIGUES, A. M. V. N. et al. Análise do efeito do uso das órteses. Rev. Ter. Ocup. Univ. São Paulo, v. 18, n. 1, p. 30-37, jan./abr., 2007.

Tabela 1 - Análise da atividade eletromiográfica dos músculos do antebraço durante o uso de órteses de punho.

\begin{tabular}{l|l}
\hline Tipos de órteses & Atividade eletromiográfica dos músculos do antebraço \\
\hline Órtese semicircular & Diminuiu a atividade da musculatura extensora \\
Órtese volar & Não alterou a atividade da musculatura extensora \\
Órtese dorsal & Não alterou a atividade da musculatura extensora \\
Órtese curta & Não alterou a atividade da musculatura extensora e aumentou a atividade da musculatura flexora \\
Órtese longa & Aumentou a atividade da musculatura extensora e flexora \\
Órtese em espiral & Não alterou a atividade da musculatura extensora e flexora \\
Órtese estática & Não alterou a atividade da musculatura extensora e flexora \\
Órtese dinâmica punho-mão & Não alterou a atividade da musculatura extensora e flexora \\
Órtese desportiva & Não alterou a atividade da musculatura extensora e flexora \\
Órtese volar & Aumentou a atividade da musculatura extensora e flexora \\
\hline
\end{tabular}

Todos os autores pesquisados avaliaram o impacto do uso da órtese de punho na atividade eletromiográfica dos músculos do antebraço em comparação à ação da mão livre de dispositivo, e a maioria dos estudos aponta para a não interferência da órtese na atividade eletromiográfica da musculatura do antebraço. No entanto, cabe ressaltar alguns aspectos que dificultam a comparação e generalização dos resultados: a população investigada, os diferentes tipos de órteses utilizados, e o tipo de tarefa executada durante o teste.

A amostra utilizada em grande parte dos estudos foi pequena, variando entre 5 e 17 participantes. A população foi composta por sujeitos de ambos os sexos, com idade média variando de 26,6 a 48,4 anos. Dos quatro estudos, três selecionaram indivíduos sem desordens do membro superior para amostragem (JANSEN et al., 1997; BULTHAUP et al., 1999; JOHANSSON et al., 2004). Apenas Burtner et al. (2003) avaliaram a ativação dos músculos do antebraço em pacientes com uma patologia específica, artrite reumatóide, com tempo médio de doença de 16.2 anos. Os resultados obtidos por Burtner et al. (2003) com pacientes portadores de artrite reumatóide apresentam-se compatíveis aos estudos que utilizaram indivíduos saudáveis. Porém, o uso de uma amostra de conveniência com participantes sem disfunção da extremidade superior e a generalização dos resultados obtidos para pessoas com um déficit funcional qualquer não é aconselhável. É possível que, para pacientes com diferentes patologias, o uso da órtese proporcione diferentes achados e, de fato, ocorra a redução da ativação da musculatura extensora do punho cumprindo seu papel de repouso da musculatura. Portanto, embora pesquisas com pessoas sem desordens do membro superior sejam importantes, é fundamental o desenvolvimento de estudos utilizando como amostra indivíduos com diferentes patologias, para que os resultados obtidos possam ser generalizados e para que se possa determinar o real efeito do uso de órteses em pessoas com comprometimentos na extremidade superior (CALLINAN, 1999).

Nestes quatro estudos, foram utilizados dez dispositivos que variaram de acordo com sua função básica (mobilização/dinâmica ou imobilização/estática), tamanho da área de suporte (longa ou curta) e localização do apoio de sustentação da articulação do punho (dorsal, volar ou coaptação), como mostra a Tabela 2. Nota-se que a maioria das órteses utilizadas eram estáticas (JANSEN et al., 1997; BULTHAUP et al., 1999; JOHANSSON et al., 2004), e apenas um estudo utilizou órtese dinâmica (BURTNER et al., 2003). De acordo com a localização do apoio de sustentação que foi oferecido ao punho, dos dez dispositivos investigados, seis eram ventrais, três envolviam a região volar e dorsal do antebraço e apenas um era dorsal. A maioria das órteses apresentou uma maior área de suporte, isto é, eram longas e, apenas três delas eram curtas.

Quando comparados os resultados intra e intergrupos levando em consideração estes três aspectos, observa-se que das três órteses estáticas volar longas, uma não alterou a atividade extensora (JANSEN et al., 1997) e duas aumentaram a atividade flexora e extensora dos músculos do antebraço (BULTHAUP et al., 1999; JOHANSSON et al., 2004). Das duas órteses estáticas volar curtas, uma não alterou a atividade extensora e aumentou a atividade flexora (BULTHAUP et al., 1999) e a outra não alterou a atividade extensora ou flexora (BURTNER et al., 2003). Aórtese estática de coaptação curta não alterou a atividade flexora ou extensora (JOHANSSON et al., 2004) e a órtese estática de coaptação longa reduziu a atividade extensora dos músculos do antebraço (JANSEN et al., 1997). A órtese estática dorsal longa não alterou a atividade extensora (JANSEN et al., 1997). As órteses dinâmicas de coaptação longa ou volar longa não alteraram a atividade da musculatura extensora ou flexora do antebraço (BURTNER et al., 2003). Comparando a órtese 
RODRigueS, A. M. V. N. et al. Análise do efeito do uso das órteses. Rev. Ter. Ocup. Univ. São Paulo, v. 18, n. 1, p. 30-37, jan./abr., 2007.

volar longa (JANSEN et al., 1997) com a órtese volar curta (BURTNER et al., 2003) observa-se o mesmo resultado. Já quando comparadas a órtese dorsal (JANSEN et al., 1997) com a volar (JOHANSSON et al., 2004) ou a órtese dinâmica (BURTNER et al., 2003) com a estática (BULTHAUPet al., 1999) os resultados não são os mesmos.

Tabela 2 - Atividade eletromiográfica de acordo com função básica, área de suporte e localização de sustentação da órtese.

\begin{tabular}{|c|c|c|c|c|}
\hline Órteses & Função básica & $\begin{array}{l}\text { Localização do apoio } \\
\text { de sustentação }\end{array}$ & Área de suporte & $\begin{array}{l}\text { Atividade eletromiográfica dos } \\
\text { músculos do antebraço }\end{array}$ \\
\hline Órtese semicircular & Estática & Volar e dorsal & Longa & Diminui a atividade da musculatura extensora \\
\hline Órtese volar & Estática & Volar & Longa & Não alterou a atividade da musculatura \\
\hline & & & & extensora \\
\hline Órtese dorsal & Estática & Dorsal & Longa & $\begin{array}{l}\text { Não alterou a atividade da musculatura } \\
\text { extensora }\end{array}$ \\
\hline Órtese curta & Estática & Volar & Curta & $\begin{array}{l}\text { Não alterou a atividade da musculatura } \\
\text { extensora e aumentou a atividade da } \\
\text { musculatura flexora }\end{array}$ \\
\hline Órtese longa & Estática & Volar & Longa & $\begin{array}{l}\text { Aumentou a atividade da musculatura extensora } \\
\text { e flexora }\end{array}$ \\
\hline Órtese em espiral & Dinâmica & Volar e dorsal & Longa & $\begin{array}{l}\text { Na alterou a atividade da musculatura extensora } \\
\text { e flexora }\end{array}$ \\
\hline Órtese estática & Estática & Volar & Curta & $\begin{array}{l}\text { Não alterou a atividade da musculatura } \\
\text { extensora e flexora }\end{array}$ \\
\hline $\begin{array}{l}\text { Órtese dinâmica } \\
\text { punho-mão }\end{array}$ & Dinâmica & Volar & Longa & $\begin{array}{l}\text { Não alterou a atividade da musculatura } \\
\text { extensora e flexora }\end{array}$ \\
\hline Órtese desportiva & Estática & Volar e dorsal & Curta & $\begin{array}{l}\text { Não alterou a atividade da musculatura } \\
\text { extensora e flexora }\end{array}$ \\
\hline Órtese volar & Estática & Volar & Longa & $\begin{array}{l}\text { Aumentou a atividade da musculatura extensora } \\
\text { e flexora }\end{array}$ \\
\hline
\end{tabular}

Aparentemente, a área de suporte ou comprimento do equipamento não interferem no percentual de esforço necessário dos músculos proximais durante a realização das tarefas pesquisadas. É fato que órteses longas devem ser preferidas, pois proporcionam maior suporte ao segmento corporal que as órteses curtas. Esta questão deve ser considerada no momento de indicação da órtese de acordo com a necessidade do cliente (BULTHAUP et al., 1999).

Por outro lado, a localização do apoio e a função básica da órtese parecem ter um papel importante no percentual de esforço necessário dos músculos do antebraço (dorsal não altera, volar pode aumentar e coaptação diminui). De todas as órteses utilizadas apenas a órtese estática de coaptação longa (semicircular) reduziu a atividade extensora da musculatura do antebraço. Pode-se supor que como este dispositivo combina as regiões volar e dorsal como apoio de sustentação e oferece maior área de suporte, acaba por cumprir, de fato, o papel de estabilização do punho com conseqüente repouso da musculatura extensora do antebraço sem interferir na função dos dedos. Ambas as órteses dinâmicas pesquisadas não alteraram a ativação muscular do antebraço. Este fato pode estar relacionado à não restrição total do movimento do punho, fazendo com que o movimento durante o desempenho das tarefas seja realizado o mais próximo possível do normal.

Ainda com relação aos tipos de órtese utilizados devese considerar que, o material utilizado para a confecção do dispositivo, o ângulo de posicionamento da articulação do punho e o uso de órteses personalizadas ou préfabricadas podem interferir no resultado esperado. Segundo Fess e Philips (1987), o uso de órteses padronizadas e comercialmente disponíveis não é recomendado, pois pode resultar na utilização de um aparelho sem a adaptação necessária para acomodar as variações anatômicas de cada indivíduo. Desta forma, todas as órteses devem ser individuais e ter como princípios para a sua confecção conceitos que estão diretamente relacionados com a durabilidade, estética e conforto do produto final. Por outro lado, Callinan (1999) aponta que as órteses pré-fabricadas podem ser mais confortáveis que as personalizadas por serem menos restritivas. Stern (1991, 1996) e Stern (1996)reforça a afirmação de Callinan, pois relata que embora qualquer órtese de 
punho tenda a reduzir a função da mão, órteses préfabricadas permitem melhor destreza e maior força de preensão do que aquelas personalizada.

Independente da indicação de uma órtese personalizada ou pré-fabricada, os materiais disponíveis para a confecção de órteses têm diferentes propriedades que influenciam as características de manuseio como conformabilidade e rigidez, e conseqüentemente, podem prover diferentes construções, ajustes e vantagens estéticas (LAU, 1998). A importância da seleção do correto material para a órtese, baseia-se no seu propósito, portanto, é fundamental que o terapeuta conheça a classificação destes materiais de acordo com sua matriz/ base, para que o comportamento particular de cada material possa ser antecipado (TROMBLY, 1995).

Quanto ao ângulo de posicionamento da articulação do punho, este não só interfere no potencial de força dos músculos flexores dos dedos como pode interferir no favorecimento do repouso e conseqüente diminuição da ativação da musculatura extensora do punho. Em geral, procura-se posicionar o punho na posição funcional, ou seja, aquela que permite maior função manual, porém não há consenso quanto ao melhor ângulo. Deshaies (2005) sugere a órtese de punho posicionada a $45^{\circ}$ de extensão para descansar a musculatura do braço. Já Fess e Philips (1987) indicam que o punho posicionado através de cockup em 10 à $30^{\circ}$ de extensão promove melhor função manual. Para as órteses de repouso da mão, Deshaies (2005) sugerem que o punho seja posicionado de 10 à $20^{\circ}$ de extensão. Contudo, Belkin e Yasuda (2005) sugerem para a mesma órtese que o punho seja colocado de 20 à $30^{\circ}$ de extensão. Para minimização da pressão no túnel do carpo autores indicam diferentes ângulos de posicionamento do punho. Melvin apud Deshaies (2005) sugere a extensão de 10 à $15^{\circ}$ do punho, enquanto Weiss et al. apud Deshaies (2005) sugerem o punho em posição neutra e Gelberman et al. apud Deshaies (2005) sugerem a flexão discreta do punho. Nos estudos pesquisados dois deles indicam o grau utilizado, diferentes entre si, e os outros não citam este aspecto.

Ressalta-se ainda que em todos os artigos as órteses foram usadas somente no momento da avaliação, e a coleta da atividade eletromiográfica, em três dos quatro estudos foi realizada em apenas um dia, sendo que somente um deles utilizou medidas em três dias consecutivos, não havendo portanto um tempo de adequação ao uso do splint. Callinan (1999) e Johansson et al. (1998) apontam para a necessidade de um tempo de adaptação ao uso da órtese, uma vez que diferentes indivíduos usam estratégias motoras específicas para adaptarem-se aos parâmetros de um novo dispositivo.

Ainda com relação aos aspectos que dificultam a comparação dos resultados deve-se ressaltar que cada estudo utilizou tarefas diferentes como contexto para o teste. Sendo a exigência biomecânica para a realização de cada uma delas completamente diferenciada.

Considerando que os estudos avaliados utilizaram diferentes tipos de órteses, população variada e tarefas distintas como contexto, e que todos esses fatores estão inter-relacionados, gerando resultados específicos, fica difícil concluir qual o real efeito deste dispositivo sobre a musculatura do antebraço. Quanto à indicação do tipo de equipamento, os achados com indivíduos saudáveis não podem ser generalizados para pacientes com diferentes patologias.

Os resultados obtidos são relevantes e podem ser utilizados especificamente para aquela população estudada e nas mesmas condições investigadas. Diante de todos os dados coletados, percebe-se que a meta de descanso proposta pelo uso das órteses pode, na prática, não ser sustentada, uma vez que a maioria das órteses utilizadas não alterou a ativação da musculatura do antebraço. Neste estudo, a adequação da indicação deste tipo de equipamento no tratamento de desordens do punho, não pôde ser verificada, sendo necessária a realização de novas pesquisas voltadas especificamente para as desordens que se deseja investigar.

\section{CONCLUSÃO}

Os resultados desta bibliografia comentada apontam para a não alteração da atividade eletromiográfica dos músculos do antebraço durante o uso de diferentes órteses de punho. No entanto, este dado deve ser analisado levando em consideração aspectos relacionados ao tipo de órtese, população e atividade realizada.

Como as evidências apresentadas neste artigo são inconclusivas, não é possível sustentar que a meta de descanso proposta pelo princípio das órteses pode ser, efetivamente, alcançada. Portanto, não é razoável, nesta revisão, sugerir qual a órtese mais indicada no tratamento das desordens do punho.

Cabe aos profissionais interessados na área de reabilitação, principalmente, os profissionais da saúde, produzirem novos estudos que favoreçam a captação da melhor evidência. E, que essas pesquisas sejam realizadas na população normal e em populações com patologias específicas, para que os resultados possam, enfim, ser generalizados. 
RODRIGUES, A. M. V. N.; MIRANDA, A. D.; PEREIRA, G. dos S.; LEAL, V. A.; ÁVILA, A. F. Analysis of the effects of the use of wrist orthoses in the forearm musculature: a commented literature review. Rev. Ter. Ocup. Univ. São Paulo, v. 18, n. 1, p. 30-37, jan./abr., 2007.

\begin{abstract}
Occupational therapists recommend wrist orthoses as a therapeutic resource in the rehabilitation program of patients with wrist disorders due to the demands of the forearm musculature. However, there are findings in the literature considering that the orthoses would increase the electromyography activity of flexor and extensor muscles, instead of reducing the load in the forearm musculature. It suggests that the aim for resting is not always achieved. Thus, the objective of this study was to perform a commented literature review through criterious analysis of articles that investigated the effects of the wrist orthoses use in the forearm musculature. A search was performed on different electronic databases, considering the period between 1995 and 2004. Based on the inclusion criteria, four articles were selected, and an analysis of the quality of the evidence was developed according to the methodology proposed by Law et al. The results of this review showed lack of consensus among the authors in relation to the electromyography activity of forearm muscles during the use of wrist orthoses.
\end{abstract}

KEY WORDS: Electromyography. Forearm. Occupational therapy. Review literature. Wrist injuries/ rehabilitation.

\section{REFERÊNCIAS}

ARMSTRONG, T. J.; CHAFFIN, D. B.; FOULKE, J. A. A methodology for documenting hand position and forces during manual work. J. Biomech., v. 12, p. 131-133, 1979.

BELKIN, J.; YASUDA, L. Ortótica. In: PEDRETTI, L. W.; EARLY, M. B. Terapia ocupacional capacidades práticas para as disfunções físicas.. 5a ed. São Paulo: Roca, 2005.

BULTHAUP, S.; CIPRINI, D. J. I.; THOMAS, J. J. An electromyography study of wrist extension orthoses and upper-extremity function. Am. J. Occup. Ther, v. 53, p. 434-440, 1999.

BURTNER, P. A.; ANDERSON, J. B.; MARCUM, M. L.; POOLE, J. L.; QUALLS, C.; PICCHIARINI, M. S. A comparison of static and dynamic wrist splints using electromyography in individuals with rheumatoid arthritis. J. Hand Ther., v. 16, p. 320$325,2003$.

CALLINAN, N. Clinical interpretation of "an electromyography study of wrist extension orthoses and upper-extremity function". Am. J. Occup. Ther., v. 53, p. 441-444, 1999.

DESHAIES, L. D. Órteses de membro superior. In: RADOMSKI, M. V.; TROMBLY, C. A. Terapia ocupacional para as disfunções físicas. 5a ed. São Paulo: Editora Santos, 2005.

FESS, E. E.; PHILIPS, C. A. Hand splinting: principles and methods. 2nd ed. St. Louis: Mosby, 1987.

HAGG, G. M.; OSTER, J.; BYSTROM, S. Forearm muscular load and wrist angle among automobile assembly line workers in relation to symptoms. Appl. Ergon., v. 28, p. 41-47, 1997.

JANSEN, C. W. S.; OLSON, S. L.; HASSON, S. M. The effect of use of a wrist orthosis during functional activities on surface electromyography of the wrist extensors in normal subjects. J. Hand Ther, v. 10, p. 283-289, 1997.

JOHANSSON, L.; BJORING, G.; HAGG, G. M. The effect of

Recebido para publicação: Fev./2007

Aceito para publicação: Mar./2007 wrist orthoses on forearm muscle activity. Appl. Ergon., v. 35, p. 129-136, 2004

JOHANSON, M. E.; JAMES M. A.; SKINNER, S. R. Forearm muscle activation during power grip and release. J. Hand Surg. (Am), v. 23, p. 938-944, 1998.

LAU, C. Comparison study of Quick Cast versus a traditional thermoplastic in the fabrication of resting hand splint. J. Hand Ther, v. 11, n. 1, p. 45-48, 1998.

LAW, M.; STEWART, D.; LETTS, L.; POLLOCK, N.; BOSCH, J.; WESTMORLAND, M. Critical review from quantitative studies. The critically appraised topic - CAT - McMaster University - Canadá, 1998. Available from: http:// www.fhs.mcmaster.ca/rehab/ebp

MATSUSHITA, N.; HANDA, Y.; ICHIE, M.; HOSHIMIYA, N. Electromyogram analysis and electrical stimulation control of paralyzed wrist and hand. J. Electromyogr. Kinesiol., v. 5, p. 117-128, 1995.

MILERAD, E. Forearm extensor and flexor muscle exertion during simulated gripping work - an electromyography study. Clin. Biomech., v. 12, p. 39-43, 1997.

MOORE, J. S.; GARG, A. Upper extremity disorders in a pork processing plant: relationship between job risk factors and morbidity. Am. Ind. Hyg. Assoc. J., v. 55, p. 703-715, 1994.

STERN, E. B. Wrist extensor orthoses: dexterity and grip strength across five styles. Am. J. Occup. Ther., v. 45, n. 1, p. 42-49, 1991.

STERN, E. B. Grip strength and finger dexterity across five styles of commercial wrist orthoses. Am. J. Occup. Ther., v. 50, p. 32-38, 1996.

TROMBLY, C. A. Occupational therapy for physical dysfunction. 4th ed. Baltimore: Williams \& Wilkins, 1995. 